\title{
Premenstrual Symptoms and Dysmenorrhoea among Muslim Women in Zaria, Nigeria
}

\author{
S. T. Sule, H. Suleiman Umar and N. H. Madugu \\ Department of Obstetrics and Gynaecology, Ahmadu Bello University Teaching Hospital, Zaria, Nigeria \\ Reprint requests to: Dr. Sa'adatu T. Sule, Ipas Nigeria, $2^{\text {nd }}$ Floor Katsina House, Ralph Shodeinde Street, \\ Central Area,Abuja,Nigeria.E-mail: saasule@yahoo.com
}

\begin{abstract}
Background/objective: To document the premenstrual and menstrual symptoms of Muslim women, with a view to providing adequate and sensitive care.

Methods: Two hundred Muslim women were interviewed at Ahmadu Bello University Teaching Hospital and Muslim Specialist Hospital, both in Zaria between August and October 2003.

Results: Premenstrual symptoms were present in $23.8 \%$ of the women and breast pain was the commonest symptom (50\%). Self-medication was practiced by those who needed medication for the premenstrual symptoms $(29.8 \%)$. Premenstrual symptoms were significantly associated with lower parity $(\mathrm{p}=0.02)$, previous $(\mathrm{p}=0.03)$ and current $(\mathrm{p}=0.01)$ contraceptive use and dysmenorrhoea $(\mathrm{p}=$ $<0.001)$. Dysmenorrhoea was present in $36.4 \%$ and was significantly associated with lower age $(\mathrm{p}=$ $0.03)$, and lower parity $(\mathrm{p}=0.01)$.

Conclusions: Health care workers and the general public need to be aware of premenstrual symptoms and dysmenorrhoea in order to provide adequate care and support that is sensitive to Muslim women's needs. Health care providers should also be aware that premenstrual symptoms are more likely to coexist with dysmenorrhoea and provide therapies that can cater for both problems whenever possible.
\end{abstract}

Key words: Premenstrual symptoms, dysmenorrhoea

\begin{abstract}
Résumé
Introduction/Objectif: Documenter les symptômes prémenstruel et menstruel des femmes muslèmes afin de fournir des soins adéquats et sensitifs.

Méthodes: Deux cents femmes muslèmes ont été sondées du centre hospitalier universitaire d'Ahmadu Bello et d'Hôpital des spécialiste des Muslèms, les deux à Zaria entre le prémier août 2003 et le 31 octobre 2003.

Résultats: Des symptômes prémenstruels étaient présent en 23,8\% des femmes et douleur de sein était le symptôme le plus ordinaire $(50 \%)$. Médicament de soi-même était mis en action par ceux qui ont besoin des drougues pour des symptômes prémenstruel (29,8\%) symptômes prémenstruels étaient principalement liés à la parité inférieure $(\mathrm{p}=0,02)$, auparavant $(\mathrm{p}=0,03)$ et actuel $(\mathrm{p}=0,01)$ l'utilisation du contraceptif et de la dysmenorrhée $(\mathrm{p}=<0,0001)$ La dysmenorrhée était présent en $36,4 \%$ et était remarquablement liée à l'âge inférieur $(\mathrm{p}=0,03)$, et parité inférieure $(\mathrm{p}=0,01)$.

Conclusion: Des médecins des soins médicaux et la publique en général sont besoin d'avoir une connaissance sur des symptômes prémenstruel et la dysmenorrhée afin de fournir des soins adéquats et de donner des soutients qui sont sensitifs visant aux besoins des femmes muslèmes. Les médecins des soins médicaux devraient également avoir connaissance qui souligne que des symptômes prémenstruels sont plus probablement de co-éxister avec la dysmenorrhée et donner des thérapies qui peuvent resoudre les deux problèmes aussi souvent que possible.
\end{abstract}

Mots-clés: Symptôme prémenstruel, dysmenorrhée

\section{Introduction}

Premenstrual and menstrual experiences vary among women being strongly affected by cultural influences. Although these conditions are not life threatening, they can seriously decrease the quality of life of many women and affect their mental health and their productivity. 1,2 The number of women seeking treatment for premenstrual symptoms is on the increase $^{1}$ especially in the Western world but the 
aetiology of the condition is poorly understood making it difficult to provide effective treatment. The term 'premenstrual syndrome' is used to describe cyclically recurring symptoms during the luteal phase of the cycle, which regress at the onset of, or during menstruation. ${ }^{1}$ There are numerous symptoms that may occur but the typical ones include somatic symptoms (such as bloatedness, breast swelling and pain, pelvic pain, headache, skin disorders, and change in bowel habits) and psychological symptoms (such as irritability, aggressiveness, depression, anxiety, inability to concentrate, hypersomnia or insomnia, change in appetite, specific food craving, change in libido, and poor coordination). ${ }^{1-5}$ During menstruation, dysmenorrhoea is a common symptom especially among adolescents and young women who usually have primary or idiopathic dysmenorrhoea, the cause of which is not clear. ${ }^{4,-9}$ Dysmenorrhoea may be secondary to conditions such as pelvic inflammatory disease, intra-uterine contraceptive devices, endometriosis, uterine fibroids, and adenomyosis. $^{10-12}$ The diagnosis of premenstrual symptoms and dysmenorrhoea is based on history alone although a physical examination should be carried out to exclude other causes of the symptoms.

13 Although the cause of these symptoms is not clear, it is believed that most of them are due to changes in the levels of some hormones and their metabolites such as prolactin, oestrogen, progesterone, endorphins, and prostaglandins, and their interactions with neurotransmitters and neurohormonal systems such as serotonin, GABA, cholecystokinin and the renin-angiotensin-aldosterone system. ${ }^{1,} 14$ Many current treatments aim to alter the levels of these hormones such as the use of oral contraceptives, progesterone, bromocriptine, prostaglandin synthetase inhibitors (especially mefenamic acid) and danazol. ${ }^{1}$ Treatments that suppress ovulation have been found to be more effective for both premenstrual symptoms and primary dysmenorrhoea. ${ }^{15,16}$

Premenstrual and menstrual problems are becoming more common due to increased awareness and the fact that women are now having fewer pregnancies resulting in more time to experience menstruation. ${ }^{1,} 3$ The cycle of pregnancybreastfeeding-new pregnancy still exists among populations of illiterate women who are thus protected from premenstrual and menstrual symptoms. ${ }^{3}$ There are many myths and taboos surrounding menstruation among various cultures that may alter the women's premenstrual and menstrual experiences and their responses to these experiences. 2, 9 This study was carried out to help in providing adequate and sensitive care.

\section{Materials and Methods}

Two hundred Muslim women attending the Gynaecology and Antenatal clinics of the Ahmadu Bello University Teaching Hospital and the Muslim Specialist Hospital, both located in Zaria, northern Nigeria, were interviewed between August and
October 2003. Pre-pubertal and post-menopausal clients were excluded. Obstetrics and Gynaecology residents conducted interviews, and the information was recorded on a structured questionnaire. Rates and comparative analyses were carried out on the data using MINITAB statistical software.

\section{Results}

The mean age of the women was 28.2 years (SD 7.3, range 17 - 45 years). The mean parity was 3.4 (SD 2.8 , range 0 - 13). Of the women interviewed, $17.6 \%$ were nulliparous, $50.3 \%$ were multiparous, and $32.2 \%$ were grandmultiparous. The mean number of abortions was 0.4 (SD 0.8 , range 0 - 4). There was no history of a previous abortion in $74.2 \%$, one previous abortion in $22.2 \%$, and three or more abortions $3.5 \%$ of the women. The mean age at first marriage was 17.2 (SD 3.4, range 12 - 29 years) and the mean age at menarche was 14.6 years (SD 1.5, range 11 - 20).

The mean duration of menses was 4.9 days (SD 1.3 , range $1-10$ ) and the mean cycle length was 28.7 days (SD 1.1, range 26 - 33). The menstrual cycles were regular in $97.5 \%$ and irregular in $2.5 \%$ of the women. Dysmenorrhoea was present in 72 women (36.4\%) and among these women; it was the primary type in $82.6 \%$ and the secondary type in $17.4 \%$.

Premenstrual symptoms were present in 46 women (23.8\%), absent in $147(76.2 \%)$ and the information was missing in the remaining 7 women. The commonest symptom was breast pain, which was present in 23 women $(50 \%)$. Twenty-one women $(45.6 \%)$ had just one premenstrual symptom while others had more than one symptom (Table 1).

The premenstrual symptoms occurred in every cycle among 19 women (40.4\%), every other cycle among $10(21.3 \%)$, every three to four cycles among $15(31.9 \%)$, and every five or more cycles among 2 $(4.3 \%)$. The symptoms occurred one week or less before the onset of the menses in all the women and they all reported that the symptoms resolved by the end of the menses. Only 14 women $(29.8 \%)$ needed medication for the premenstrual symptoms and of these, $10(71.4 \%)$ took paracetamol, 2 (14.3\%) took Buscopan ${ }^{(\mathrm{R})}$, one $(7.1 \%)$ took piroxicam, and one $(7.1 \%)$ took traditional medication. Medications were taken without consulting any health care provider (self-medication).

There was no significant association between presence of premenstrual symptoms and present age, age at menarche, last childbirth, and duration of menses or cycle length. The mean age at first marriage was higher for women who had premenstrual symptoms compared to those who did not have such symptoms (Table 2).

The mean age was significantly lower for women who had dysmenorrhoea compared to those without dysmenorrhoea but dysmenorrhoea was not significantly associated with age at menarche, age at first marriage, duration of menses, or cycle length (Table 3).

A significantly higher proportion of women 
who had premenstrual symptoms $(25 \%)$ were previous $(36.4 \%)$ or current $(25 \%)$ contraceptive users compared to those who did not have symptoms (20.5\% and $10.3 \%$ respectively). A significantly higher proportion of women who had premenstrual symptoms were nulliparous $(30.4 \%)$ compared to those who did not have symptoms (14.4\%). Similarly, grandmultiparae formed a significantly lower proportion among women who had premenstrual symptoms (19.6\%) compared to women who had no symptoms $(34.9 \%)$. A significantly higher proportion of women who had premenstrual symptoms also suffered from dysmenorrhoea (76.1\%) compared to women who had no premenstrual symptoms $(24.5 \%)$. There was no significant association between presence of premenstrual symptoms and previous marriages, previous abortions, type of dysmenorrhoea or cycle regularity (Table 4).

Menstrual pain was significantly associated with parity with $60 \%$ of nulliparous women reporting menstrual pain compared to $32 \%$ of multiparous women and $30 \%$ of grandmultiparous women. The presence of menstrual pain was not significantly associated with previous or current contraceptive use, previous marriages, previous abortions, or cycle regularity (Table 4).

A significantly higher proportion of women (66.7\%) who had secondary dysmenorrhoea had used contraceptives previously compared to those (19.3\%) who had primary dysmenorrhoea $(\chi 2=11.15$, DF $=1$, $\mathrm{p}=0.001)$. Similarly, current contraceptive use among women $(50.0 \%)$ who had secondary dysmenorrhoea was significantly higher than it was among women (7.0\%) who had primary dysmenorrhoea $(\chi 2=14.78, \mathrm{DF}=1, \mathrm{p}=<0.001)$ (Table 5).
There was no significant association between the type of dysmenorrhoea and contraceptive method used previously $(\chi 2=5.04, \mathrm{DF}=4, \mathrm{p}=0.28)$ or currently $(\chi 2=3.75, \mathrm{DF}=3, \mathrm{p}=0.29)$. There was also no significant association between the type of dysmenorrhoea and cycle regularity $(\chi 2=1.52$, DF $=$ $1, \mathrm{p}=0.22)$ or number of previous marriages $((\chi 2=$ $2.46, \mathrm{DF}=3, \mathrm{p}=0.48)$.

The type of dysmenorrhoea was significantly associated with parity $(\chi 2=17.24, \mathrm{DF}=2, \mathrm{p}=$ $<0.001$ ) with primary dysmenorrhoea being present in $100 \%$ of the nulliparous women who reported dysmenorrhoea, $90 \%$ of multiparous women, and $52.6 \%$ of the grandmultiparous women. Secondary dysmenorrhoea was present in none of the nulliparous women, $10 \%$ of the multiparous women and $47.4 \%$ of the grandmultiparous women.

The regularity of the menstrual cycles was not significantly associated with previous $(\chi 2=0.70, \mathrm{DF}$ $=1, \mathrm{p}=0.40)$ or current $(\chi 2=0.19, \mathrm{DF}=1, \mathrm{p}=0.66)$ contraceptive use.

Table 1: Premenstrual symptoms among 46 Muslim women in Zaria

\begin{tabular}{lll}
\hline Symptom & $\begin{array}{l}\text { Occurring } \\
\text { alone }(\%)\end{array}$ & $\begin{array}{l}\text { Occurring with } \\
\text { other symptoms } \\
(\%)\end{array}$ \\
\hline Breast pain & $11(23.9)$ & $23(50.0)$ \\
Headache & $2(4.3)$ & $12(26.1)$ \\
Nausea & $2(4.3)$ & $10(21.7)$ \\
Irritability & $4(8.7)$ & $6(13.0)$ \\
Bloating & - & $6(13.0)$ \\
Moodiness & $2(4.3)$ & $5(10.9)$ \\
Palpitations & - & $3(6.5)$ \\
Low backache & - & $1(2.2)$ \\
\hline
\end{tabular}

Table 2: Factors associated with premenstrual symptoms in Muslim women in Zaria

\begin{tabular}{lllll}
\hline Variable & $\begin{array}{l}\text { Premenstrual symptoms } \\
\text { present (means) }\end{array}$ & $\begin{array}{l}\text { Premenstrual symptoms } \\
\text { absent (means) }\end{array}$ & $\begin{array}{l}\text { Difference in } \\
\text { means }(95 \% \text { CI) }\end{array}$ & $\begin{array}{l}\text { T value } \\
(\mathrm{p} \text { value })\end{array}$ \\
\hline Age & 26.9 years & 28.3 years & $1.4(-1.04,3.82)$ & $1.14(0.26)$ \\
Age at $1^{\text {st }}$ marriage & 18.0 years & 16.9 years & $1.1(-2.23,-0.04)$ & $2.06(0.04)$ \\
Age at menarche & 14.5 years & 14.5 years & $0.0(-0.50,0.55)$ & $0.09(0.93)$ \\
Last childbirth & 31.5 months & 32.5 months & $1.0(-13.52,15.52)$ & $0.14(0.89)$ \\
Duration of menses & 5.2 days & 4.8 days & $0.4(-0.81,0.02)$ & $-1.91(0.06)$ \\
Cycle length & 28.6 days & 28.7 days & $0.1(-0.22,0.529)$ & $0.81(0.42)$ \\
\hline
\end{tabular}

CI: confidence intervals

Table 3: Factors associated with dysmenorrhoea in women in Zaria

\begin{tabular}{lllll}
\hline Variable & $\begin{array}{l}\text { Dysmenorrhoea present } \\
(\text { means })\end{array}$ & $\begin{array}{l}\text { Dysmenorrhoea absent } \\
(\text { means })\end{array}$ & $\begin{array}{l}\text { Difference in } \\
\text { means (95\% CI) }\end{array}$ & $\begin{array}{l}\text { T value } \\
(\mathrm{p} \text { value })\end{array}$ \\
\hline Age & 26.6 years & 29 years & $2.4(-4.50,-0.27)$ & $2.23(0.03)$ \\
Age at $1^{\text {st }}$ marriage & 17.7 years & 16.9 years & $0.8(-0.21,1.74)$ & $1.54(0.12)$ \\
Age at menarche & 14.6 years & 14.5 years & $0.1(-0.35,0.51)$ & $0.36(0.72)$ \\
Last childbirth & 27.5 months & 35.6 months & $8.1(-19.17,2.94)$ & $-1.45(0.15)$ \\
Duration of menses & 4.9 days & 4.9 days & $0.0(-0.34,0.43)$ & $0.23(0.82)$ \\
Cycle length & 29.2 days & 27.9 days & $1.3(-0.77,3.40)$ & $1.25(0.21)$ \\
\hline
\end{tabular}


Table 4: Factors associated with premenstrual symptoms and dysmenorrhoea in Muslim women in Zaria

\begin{tabular}{lllll}
\hline Variable & \multicolumn{2}{l}{ Premenstrual symptoms } & Dysmenorrhoea & \\
\hline & $\chi^{2}$ value (DF) & P value & $\chi 2$ value (DF) & P value \\
\cline { 2 - 4 } Parity & $7.59(2)$ & 0.02 & $10.12(2)$ & 0.01 \\
Previous contraceptive use & $4.61(1)$ & 0.03 & $0.55(1)$ & 0.46 \\
Current contraceptive use & $6.21(1)$ & 0.01 & $0.09(1)$ & 0.77 \\
Previous marriage & $2.58(4)$ & 0.63 & $3.54(4)$ & 0.47 \\
Previous abortions & $4.64(2)$ & 0.10 & $4.23(4)$ & 0.38 \\
Dysmenorrhoea & $40.11(1)$ & $<0.001$ & $\mathrm{~N} / \mathrm{A}$ & $\mathrm{N} / \mathrm{A}$ \\
Type of dysmenorrhoea & $0.01(1)$ & 0.91 & $\mathrm{~N} / \mathrm{A}$ & $\mathrm{N} / \mathrm{A}$ \\
Cycle regularity & $0.002(1)$ & 0.96 & $0.03(1)$ & 0.87 \\
\hline
\end{tabular}

DF: degrees of freedom; N/A: not applicable

Table 5: Factors associated with type of dysmenorrhoea in Muslim women in Zaria

\begin{tabular}{|c|c|c|c|c|}
\hline Variable & $\begin{array}{l}\text { Primary } \\
\text { dysmenorrhoea } \\
\text { (means) }\end{array}$ & $\begin{array}{l}\text { Secondary } \\
\text { dysmenorrhoea } \\
\text { (means) }\end{array}$ & $\begin{array}{l}\text { Difference in means (95\% } \\
\text { confidence intervals) }\end{array}$ & $\begin{array}{l}\text { T value } \\
\text { ( } \mathrm{p} \text { value) }\end{array}$ \\
\hline Age & 25.7 years & 32.1 years & $6.4(-9.89,-2.84)$ & $-3.74(0.001)$ \\
\hline Age at menarche & 14.5 years & 14.8 years & $-0.3(-1.260,0.631)$ & $-0.71(0.490)$ \\
\hline Age at first marriage & 17.9 years & 16.0 years & $1.9(-0.57,4.21)$ & $1.64(0.124)$ \\
\hline Duration of menses & 4.8 days & 5.1 days & $0.3(-.966,0.442)$ & $-0.78(0.447)$ \\
\hline Cycle length & 28.2 days & 34.2 days & $6.0(-17.25,5.28)$ & $-1.17(0.267)$ \\
\hline
\end{tabular}

\section{Discussion}

The commonest premenstrual symptom among Muslim women in Zaria is breast pain, which was present in $50 \%$ of the women as the only symptom or in combination with other symptoms. This is one of the commonest premenstrual symptoms reported in previous studies although the single most common symptom varies among different population probably due to cultural influences. ${ }^{3-5}$ Other symptoms reported by women in Zaria included headache, nausea, irritability and bloating. Among women who reported premenstrual symptoms, these symptoms occurred every cycle in $40.4 \%$ and every other cycle in $21.3 \%$. The symptoms occurred within one week of the onset of menses in all the women and they all reported that the symptoms resolved by the end of the menses. These features are in keeping with premenstrual syndrome as has been described previously. ${ }^{1}$ All the women $(29.8 \%)$ who needed medication for relief of the premenstrual symptoms did not seek medical attention and commonest drug used as paracetamol. Traditional medication was used by $7.1 \%$ of those who needed medication. These findings are in keeping with previous reports of women not seeking medical attention for menstrually related symptoms because menstruation is considered highly personal and secretive or because of fear, preferring selfmedication and alternative therapies. ${ }^{4,9,17}$

The mean age at first marriage was significantly higher for women who had premenstrual symptoms (18 years) compared to women who did not (16.9 years) probably because those who married earlier may have had less education or exposure and therefore lower awareness of their bodies. Another possible explanation may be that those who got married at older ages, because of more education or better awareness of health issues, are more likely to seek medical attention including antenatal clinic attendance where they may receive information regarding issues surrounding the menstrual cycle. This may also be the explanation for the significant association between premenstrual symptoms and previous or current contraceptive use - women utilizing contraceptive services are more likely to be better informed about reproductive health issues and be more aware of their bodies. There is also the possibility of the contraceptives being responsible for the premenstrual symptoms due to hormonal changes especially as hormonal factors have been implicated in the aetiology of this condition. ${ }^{1,14}$ Premenstrual symptoms were also significantly more common in nulliparous women possibly because they do not have the protective effect of pregnancy-breastfeeding-new pregnancy cycle that occurs in the grandmultiparae as reported previously. ${ }^{3}$ This is supported by the fact that grandmultiparae formed the lowest proportion of women who had premenstrual symptoms $(p=0.02)$. The presence of premenstrual symptoms was strongly associated with dysmenorrhoea $(\mathrm{p}=<0.001)$ as has been reported previously ${ }^{18}$ suggesting the possibility of a common aetiology probably related to prostaglandins. Prostaglandin synthetase inhibitors (particularly mefenamic acid) have been shown to be beneficial in managing both dysmenorrhoea and premenstrual symptoms like headache, depression, tension and irritability. ${ }^{1}$

Dysmenorrhoea, a common symptom during menses, 4, 6, 9, 18 was present in about $36 \%$ of the women interviewed and was of the primary type in $82.6 \%$ of these women. The mean age for women who had dysmenorrhoea (26.6 years) was 
significantly lower than it was for women who did not have dysmenorrhoea (29 years). Similarly, a higher proportion of nulliparous women $(60 \%)$ reported dysmenorrhoea compared to multiparous (32\%) and grandmultiparous $(30 \%)$ women. This is not surprising as majority of women in this study had primary dysmenorrhoea, which is more common in younger women who are also more likely to be nulliparous. The presence of secondary dysmenorrhoea was significantly associated with previous or current contraceptive use probably because those who were contraceptive users were older and thus more likely to have conditions that lead to secondary dysmenorrhoea such as uterine fibroids. $^{15}$ Secondary dysmenorrhoea is one of the side effects of the intra-uterine device, especially the inert devices that are commonly used in this environment $^{10,} 12$ and this may also explain the significant association of this type of dysmenorrhoea with contraceptive use.

Premenstrual symptoms and dysmenorrhoea exist among Muslim women in Zaria and health care providers catering to this population and other similar populations should be aware of these symptoms and offer sensitive care and support when required. Health care providers should also be aware that premenstrual symptoms are more likely to coexist with dysmenorrhoea and provide therapies that can cater for both problems whenever possible. Public awareness on this issue should be increased so that women and their families will respond appropriately when such symptoms occur. This can be achieved by teaching women coping strategies in Islamic schools as well as teaching men during sermons about the need to be supportive of their spouses when such symptoms (especially moodiness and irritability) arise. This will help to improve the mental and physical health of women and also prevent marital discord and ensure happy families and communities.

\section{References}

1. O'Brien PMS. The premenstrual syndrome. A review. J Reprod Med 1985; 30: 113-126

2. McHichialami KH, Tahiri SM, Moussaoui D, et al. Assessment of premenstrual dysphoric disorder symptoms: population of women in Casablanca (abstract). Encephale 2002; 28: 252230

3. Cenac A, Maikibi DK, Develoux M. Premenstrual syndrome in Sahelian Africa. A comparative study of 400 literate and illiterate women in Niger. Trans R Soc Trop Med Hyg 1987; 81: 544-547
4. Cronje HS, Krintzinger IE. Menstruation: symptoms, management and attitudes in university students. Int J Gynecol Obstet 1991; 35:147-150

5. Khella AK. Epidemiologic study of premenstrual symptoms. J Egypt Public Health Assoc 1992; 67: 109-118

6. Thomas KD, Okonofua FE, Chiboka O. A study of the menstrual patterns of adolescents in Ile-Ife, Nigeria. Int J Gynecol Obstet 1990; 33: 31-34

7. Odujinrin OM, Ekunwe EO. Epidemiologic survey of menstrual patterns amongst adolescents in Nigeria. West Afr J Med 1991; 10: 244-249.

8. Zurayk H, Khattab H, Younis N, El-Mouelhy M, Fadle M. Concepts and measures of reproductive morbidity. Health Trans Rev 1993; 3: 17-40

9. Walraven G, Ekpo G, Coleman R, et al. Menstrual disorders in rural Gambia. Stud Fam Plann 2002; 33: 261 - 268

10. Serour GI, Hamza A, El Sheikha Z, Hefnawi FI. Clinical evaluation of U-coil progesterone releasing device versus inert U-coil IUD. Popul Sci 1982; 3: 121-135

11. Omu AE, Ihejirika IJ, Tabowei G. Management of uterine fibroids at the University of Benin Teaching Hospital. Trop Doct 1984; 14: 82-85

12. Farr G, Amatya R, Acosta M, et al. Clinical performance of the TCu 380A and Lippes loop IUDs in three developing countries. Contraception 1995; 52: 17-22

13. Freeman EW. Premenstrual syndrome and premenstrual dysmorphic disorder: definitions and diagnosis. Psychoneuroendocrinology 2003; 28 (suppl 3): 25-37

14. Halbreich U. The etiology, biology, and evolving pathology of premenstrual syndromes. Psychoneuroendocrinology 2003; 28 (suppl 3): 55-99

15. Magowan B. Menorrhagia and dysmenorrhoea. In: Magowan B. Churchill's pocketbook of obstetrics and gynaecology. Churchill Livingstone, Edinburgh1997;179-181

16. Kouri EM, Halbreich U. Hormonal treatments for premenstrual syndrome. Drugs Today 1998; 34: 603-610

17. Domoney CL, Vashisht A, Studd JW. Premenstrual syndrome and the use of alternate therapies. Ann N Y Acad Sci 2003; 997: 330340

18. Shye D, Jaffe B. Prevalence and correlates of perimenstrual symptoms: a study of Israeli teenage girls. J Adolesc Health 1991; 12: 217224 